\title{
The Impact of Project Work and the Writing Process Method on Writing Production
}

\section{El impacto del trabajo por proyecto y el método de proceso de la escritura en la producción escrita*}

\author{
Marcela Díaz Ramírez \\ mache9250@hotmail.com \\ Universidad de Cundinamarca, Colombia
}

This article presents the outcomes of an investigation whose main goal was to implement the methodology of project work and a process approach in order to improve writing production in an English class of Colombian university students since their diagnostic tests showed that their written production had the lowest score. Based on data collected, four factors were developed in the process of learning to write when project work and the writing process method are implemented: accuracy, fluency, integrative language skills, and a positive perception towards writing.

Key words: English language learning, project work, process writing

Este articulo presenta los resultados de una investigación cuyo propósito fue implementar la metodología de trabajos por proyectos y el enfoque basado en el proceso para mejorar la producción de la escritura en la clase de inglés de estudiantes colombianos universitarios ya que sus pruebas diagnósticas mostraron que la producción escrita obtuvo el desempeño más bajo. De acuerdo a la información recolectada, cuatro factores fueron desarrollados en el proceso de aprendizaje de la escritura cuando se implementa el trabajo por proyectos y el método de proceso de la escritura: la precisión, la fluidez, las habilidades lingüísticas integradas y una percepción positiva hacia la escritura.

Palabras clave: aprendizaje de la lengua inglesa, proceso de la escritura, trabajo por proyectos

* Received: January 8, 2014. Accepted: June 26, 2014.

How to cite this article (APA $6^{\text {th }}$ ed.):

Díaz Ramírez, M. (2014). The impact of project work and the writing process method on writing production.

HOW, A Colombian Journal for Teachers of English, 21(2), 31-53. 


\section{Introduction}

Teachers put forth great effort when attempting to develop effective teaching methods to promote learning. Yet, when assessing student learning, the results are oftentimes rather grim. I applied a diagnostic test for English classes at the start of the semester in a Colombian public university. In this case-a level-III English class- the results of the diagnostic test were low. In a classroom of 24 students and using a scale of $0-100$, the statistics from this exam showed that 80 percent of the students did not pass the exam, 20 percent of the students passed the exam with low scores, and not a single student received an outstanding score. The conclusion from these statistics is that learning a new language requires more than minimal effort.

The research was also based on writing skills because students had the lowest proficiency level concerning writing skills and, in fact, when students were asked about the diagnostic test, they admitted that the most difficult portion of that test was the writing section. Consequently, a pedagogical intervention was carried out to help students with their writing difficulties through the use of project work and the writing process method as a means of providing enough feedback.

The article is organized as follows: The first part presents definitions of project work and the writing process method, the second describes the study, and the third presents the results, discussion, and some conclusions.

\section{Literature Review}

\section{Project-Based Learning}

Project-based learning is more than the simple incorporation of a project; it is experiential and meaningful learning: "It is a versatile vehicle for fully integrated language and content learning” (Stoller, 1997, p. 3). Haines (1989) states that project work is a learning experience which seeks to provide students with knowledge from various areas of learning. It is "transverse and integrative," and can be critically and creatively applied to real life situations. These aspects can be kept in mind to foster meaningful written production because students are not only learning a language, but are also learning through a language. In other words, this process involves multi-skill activities which focus on a theme of interest rather than on specific language tasks.

Legutke and Thomas (1991) define a project as:

A theme and task-centered mode of teaching and learning which results from a joint process of negotiation between all participants. It allows for a wide scope of self-determined action for both the individual and the small group of learners within a general framework of a plan which defines 
goals and procedures. Project learning realizes a dynamic balance between a process and a product orientation. (p. 160)

A product orientation stresses results over process and knowledge at a basic factual or procedural level. A process orientation is more complex, allowing greater understanding and application, learning to think and learning to learn (Bluestein, 2001). Both process and product are important in learning but it is necessary to focus primarily on the process because focusing on a process level can have a great impact on the quality of the final product.

Project work requires an active role in which students are doing authentic and motivational tasks in order to reach a common goal where the language is the means rather than the end since an end-product is not the only goal when implementing project work. In this sense, students can be interested in getting their final outcomes but teachers are interested in providing opportunities where students can improve their language skills such as speaking, writing, reading, and listening by means of reading and listening about their culture, writing their own recipes, and recording videos for talking about them. Also, their affective factors such as attitudes towards learning and social factors such us collaborative work can benefit from the implementation of project work. In spite of the fact that there were no fixed lesson plans, some stages were followed to develop this study. According to Fried-Booth (2002) there are eight stages:

1. Stimulus. It is an initial discussion of ideas, comments, and suggestions about projects.

2. Definition of the project objective. It is when students and a teacher give suggestions and negotiate the project.

3. Practice of language skills. It is the language preparation for doing a project.

4. Group activities. They include gathering information inside or outside the classroom in groups.

5. Organization of materials. Students dedicate some time to organize materials in order to develop the final outcome.

6. End product. It is when students develop the end product of the project.

7. Final presentation. It depends on the form of the end product.

8. Feedback. It is the evaluation and classroom feedback sessions which can take place at any moment of the project. At this stage, Stoller (2002) points out that learners can reflect on the language they want to master to complete the project because the teacher provides several opportunities to recognize weaknesses and thus strengthen skills. During the implementation of this study, students were given recommendations for increasing their production. The stages of this article will be explained in the Study Procedures. 


\section{The Writing Process Framework}

Hyland's proposal (2003) can be kept in mind since it is one of the most recognized models for implementing the writing process in the classroom. It consists of

A topic selection, (by teachers or students); prewriting (through brainstorming, collecting data, note taking, outlining, etc.); composing (by getting the ideas on the paper); responding to drafts (by teacher or peer assessment of ideas, organization, and style); revising (reorganizing, refining ideas, adjusting to the audience, etc.); responding to revisions (by teacher or peer who check ideas, organization, and style); proofreading and editing (checking and correcting the form, the layout, etc.); evaluation (teacher evaluates the process); publishing (by class presentation, websites, etc.); and follow-up tasks (to address weaknesses, metacognitive awareness, etc.). (Hyland, 2003, p. 11)

Writing is identified as a process rather than a product. The writing process involves pedagogical techniques which include brainstorming, planning, multiple drafting, peer collaboration, delayed editing, and portfolio assessment. In fact, this type of writing promotes meaningful learning by making learners more aware of cognitive processes as a central activity in writing as well as "stressing the need to develop students' abilities to plan, define a rhetorical problem, propose and evaluate solutions" (Hyland, 2003, p. 10). As this model makes use of the process of pre-writing, drafting, revising, and editing, it offered a great opportunity to expose students to meaningful feedback and developed their written production.

\section{Research Question}

What are the effects of the implementation of project work on students' written production in an English as a foreign language (EFL) university class?

\section{Sub-Question}

What is the difference between students' written production before the implementation of project work and students' written production after the implementation of project work in an EFL university class?

The purposes of these inquiries were to observe and describe the effects of implementing a project in students' written production in an EFL university class and specifically to evaluate and compare students' writing production before and after the implementation of a project through several types of texts. 


\section{Method}

\section{Type of Research}

A case study was carried out to answer the previous questions. This method involved a deep examination of a single event: in this case, the effects of project work on students' written production. In other words, a case study focuses on what is unique. The participants involved in this study were students majoring in environmental engineering. As Wallace (1998) clarifies the concept, "by case study, we mean the systematic investigation of an individual case, whether that refers to one teacher, one learner, one group, one class, or whatever" (p. 47). The author highlights that the case study can generate more human interests as this study did because it dealt with the effects on students' written production.

\section{Setting and Participants}

A project was developed at a public university located in a town called Facatativá near Bogotá (the capital of Colombia). This research was applied to students of third level English who signed up for environmental engineering (third semester). Not all the students studied environmental engineering as some of them came from other degree programs for various reasons such as being very behind in their studies, failing other subjects, catching up on their studies, and so on. It means that English classes can be registered for in any School of the University. There were 24 students in the third-level English class. Most of them came from public schools and belonged to low income families.

\section{Data Collection}

In order to collect data, student artifacts such as their written production were gathered and analyzed by taking notes with the support of other instruments. For instance, field notes are instruments in which there are teachers' verbal descriptions and comments regarding the development of class in terms of feelings, reactions, and progress that provided information about students' writing as shown in the following extract:

The students decided the most appropriate questions to ask a foreigner. Some students said they could not be very personal and therefore it was necessary to create general culture questions because possible some information about Colombia is not well known by a foreigner...In consensus, the following questions were written by them on the board:

What is your name?

How long have you been here in Colombia?

What do you like about Colombia?

What is your favorite food? 
What is your least favorite food?

Have you ever eaten tamales? Ajiaco? Arroz con camarones? Mamona?

Do you like Colombia food?

What are the typical dishes of your country? (Field notes)

Videos recordings "allow teachers to observe many facets of their teaching and provide heuristic and accurate information" (Hopkins, 2002, p. 132). They were also used to save the class' development about students' writing and oral production.

Furthermore, questionnaires are instruments to learn students' opinions and reflections about their learning process, that is, whether they considered they were actually learning anything or making progress and what particular aspects were difficult for them in the process as shown in Figure 1.

\section{Study Procedures}

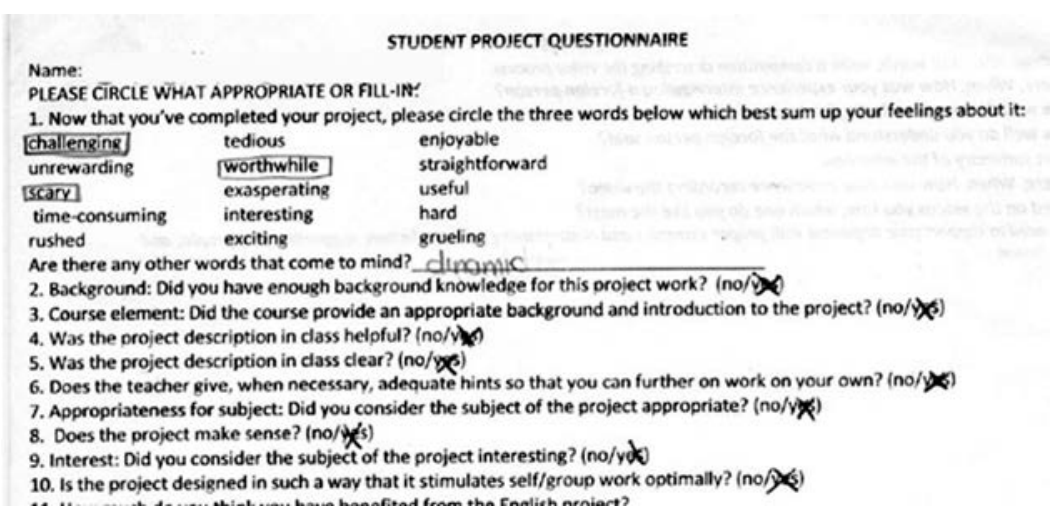

Figure 1. Questionnaire

As explained before, Fried-Booth (2002) includes some stages where teachers and students agree on a topic and a final outcome; they practice language skills required for gathering information and present a final product of their work. The stages of project work were developed and adapted according to the needs and requirements of teacher and students in their English class. 


\section{Stimulus}

After the diagnosis tests' results, the teacher involved students in a session whereby students were able to express their opinions about the test; they also talked about their academic experiences and the subjects at the university. Afterwards, there was an initial discussion of ideas and suggestions about projects in order to change the traditional methodologies they had already experienced at the university.

\section{Implementation of the Project}

After explaining the general idea about the project, the teacher proposed food as a main topic and students agreed with it. According to them, food was an interesting topic and meaningful activities could be done with it. Students were asked to organize themselves in groups and to propose ideas about what they wanted to include in the project. Most of their ideas were related to both Colombian and international food. The students and the teacher organized a general work plan (see Table 1).

Table 1. Work Scheme

\begin{tabular}{|c|c|c|c|c|}
\hline Work groups & Main activities & Time & $\begin{array}{c}\text { Main } \\
\text { objectives }\end{array}$ & Resources \\
\hline $\begin{array}{l}\text { Group 1: six } \\
\text { students } \\
\text { Group 2: three }\end{array}$ & $\begin{array}{l}\text { Colombian } \\
\text { culture and food } \\
\text { by regions. }\end{array}$ & $\begin{array}{l}\text { Term one: } 5 \\
\text { weeks }\end{array}$ & Learn English & \multirow{3}{*}{$\begin{array}{l}\text { Internet } \\
\text { Food } \\
\text { Movies } \\
\text { Books } \\
\text { Materials for } \\
\text { presentations }\end{array}$} \\
\hline $\begin{array}{l}\text { students } \\
\text { Group 3: five }\end{array}$ & $\begin{array}{l}\text { Typical food } \\
\text { recipes }\end{array}$ & $\begin{array}{l}\text { Term two: } 4 \\
\text { weeks }\end{array}$ & $\begin{array}{l}\text { Learn about } \\
\text { food }\end{array}$ & \\
\hline $\begin{array}{l}\text { Group 4: five } \\
\text { students } \\
\text { Group 5: five } \\
\text { students }\end{array}$ & $\begin{array}{l}\text { Reports about } \\
\text { food (video) }\end{array}$ & $\begin{array}{l}\text { Term three: } 4 \\
\text { weeks }\end{array}$ & Create a video & \\
\hline
\end{tabular}

\section{Practice of Language Skills and Group Activities}

This stage includes language functions and language structures to carry out students' projects. The language skills were developed through three main activities: (1) talking about Colombian culture through food, (2) describing Colombian recipes, and (3) interviewing a 
foreigner about food. Each main activity was planned for four weeks but some activities took six weeks. Figure 2 represents students' proposals for producing.

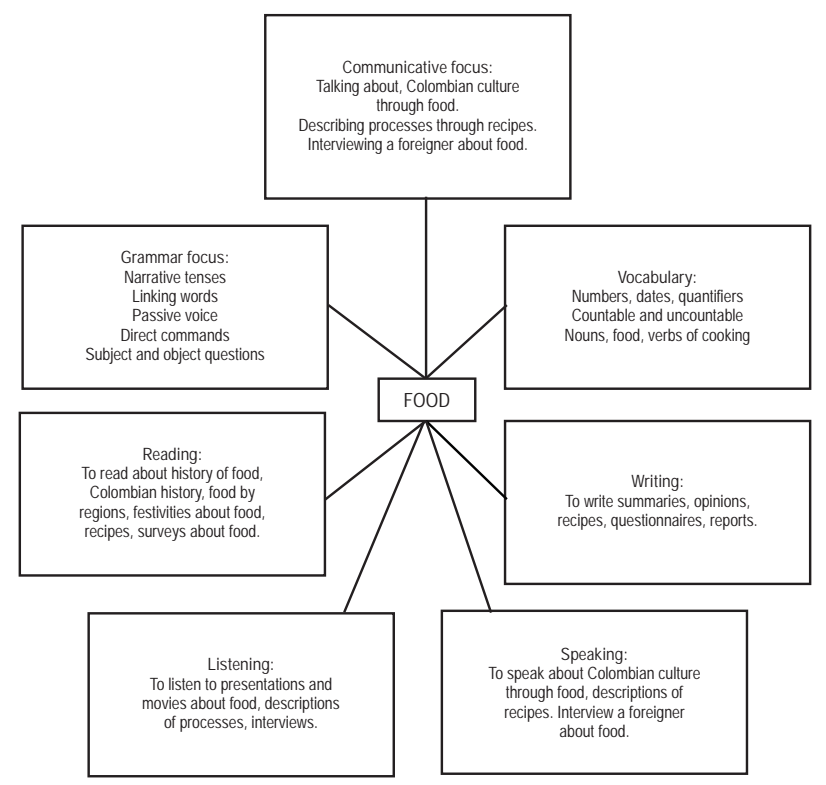

Figure 2. Students' Proposal (Adapted From Ribé \& Vidal, 2003)

\section{Final Presentation and Evaluation}

At the end of this study, the students were really enthusiastic to show what they had done in terms of food and there were positive comments about each video. For example, students used expressions such as "Finally we got it!" "We could present our recipes," "Wonderful work," "We did not think we could do [that] in a video...teacher"1 (Field notes). Evaluation was not only a responsibility of the teacher, but students and partners could participate in feedback using self-assessment and peer-feedback. In this case, students were engaged in feedback sections and their writings were revised from drafts to final versions of compositions almost every class.

\footnotetext{
1 These sentences have been translated from Spanish.
} 


\section{Role of Teacher and Students}

It is important to highlight that implementation of the project required both following some stages and awareness of roles inside the classroom. Based on Fried-Booth (2002), a teacher is the facilitator. The role as a teacher involved a big responsibility and since I was a coordinator, I was a figure constantly evaluating and monitoring the language being used in students" oral and written production. The students are active "doers" of learning, that is, they were able to construct their own knowledge based on the meaningful interaction they experienced. Specifically, we gradually shifted responsibility to the students in order to get a metacognition process going, peer assessment and cooperative work.

\section{Discussion}

As I pointed out in the diagnostic test description, most students were beginner writers. However, their written proficiency level was marked with different grades used to assess students' compositions, which were very poor, poor, acceptable, and good. Due to length limits in order to see the effects of project work in her written production, only a sample of one student will be shown in the following lines.

\section{Graded High in the Diagnostic Test Writing}

Student 1 wrote a short but well-organized text on the diagnostic test and she a total score of 3.0/5.0. Her first composition had an organized structure in spite of some errors. Concerning form, there were only a few problems with word choice, word tense, and word form. The text showed some important ideas for supporting the text (see Table 2).

In the second composition, "How to Learn English," the text had coherent ideas but there were often problems with spelling, word form, word choice, punctuation, and the omission of words:

Nowadays_English is an important language for our daily lives because _ is very used in bussiness, work, studys, travelling_ and _ also is the language of the economy, culture, politics and science. Because of it to learn english we should have differents strategis and we should use it every day.

The text was well-organized containing an introduction, arguments, and conclusion, but the evidence required specific examples.

In the second draft, she corrected almost every grammar mistake:

Nowadays_ English is an important language for our daily lives because _ is very common in business, work, studies, travelling, and it also is the language of the economy, culture, politics and science. Then_ for learning English we should have different strategies and we should use them every day. 
Table 2. First Written Production Recurrent Errors

\begin{tabular}{|l|c|}
\hline \multicolumn{1}{|c|}{ Type of Error } & Recurrence \\
\hline Spelling & 1 \\
\hline Grammar/Vocabulary & 12 \\
\hline Punctuation/Capitalization & Some problems \\
\hline Run-on Sentences & - \\
\hline Word-count & $90 / 150$ \\
\hline Overall Score & Good \\
\hline
\end{tabular}

She used to have problems with the subject-verb agreement for third person, but she needed instructions and included more specific examples in her text.

In her final draft, she wrote a text with supporting ideas. The structure was thoroughly developed and the sentence structure was correct even though there were some problems with punctuation and word order:

Nowadays_ English is an important language for our daily lives because it is very common in business, work, studies, travelling, and it also is the language of the economy, culture, politics and science. Then_ for learning English we should have different strategies and we should use them every day.

The position was clearly stated in the conclusion: "Every time we use more and more those skills_ probably English will be not a foreign language, nor difficult to learn; On the contrary, it will be part of our lives. So enjoy it!" Her composition was not a complete coherent and cohesive text but it was accurate and had the proper tone that enhanced persuasiveness toward the reader. Table 3 shows the progress made in each composition.

In the third composition, "History of Colombian Food," there were some problems with spelling, word choice, punctuation, and omission of words:

Colombia has many rates of dishes. People in Colombia are happy _ as well as_kind; besides_each region has feature things and special custom. Colombia food is influenced by Asian cuisine, Arabic cuisine, but especially by Spanish _ since this country conquered populations indigenous that were inhabitants of those lands.

The ideas, however, were well-organized and she used linking words and supporting ideas. In the second draft, she corrected some mistakes but there were a couple of problems with punctuation, word order, and word choice: 
Colombia has many rates of dishes. People in Colombia are happy _ as well as_kind; besides_each region has typical and special custom. Colombia food is influenced by Asian cuisine, Arabic cuisine, but especially by Spanish _ since this country conquered populations indigenous that were inhabitants of those lands.

Table 3. Second Written Production Overall Recurrent Errors

\begin{tabular}{|l|c|c|c|c|c|c|c|c|}
\hline $\begin{array}{c}\text { How to } \\
\text { Learn } \\
\text { English }\end{array}$ & Spelling & Grammar & $\begin{array}{c}\text { Voca- } \\
\text { bulary }\end{array}$ & $\begin{array}{c}\text { Punctua- } \\
\text { tion }\end{array}$ & $\begin{array}{c}\text { Capitali- } \\
\text { zation }\end{array}$ & $\begin{array}{c}\text { Run-on } \\
\text { sentences }\end{array}$ & Total & $\begin{array}{c}\text { Word- } \\
\text { count }\end{array}$ \\
\hline Draft 1 & 7 & 13 & 3 & 6 & 3 & 0 & 32 & 138 \\
\hline Draft 2 & 0 & 5 & 2 & 3 & 0 & 0 & 10 & 200 \\
\hline $\begin{array}{l}\text { Final } \\
\text { version }\end{array}$ & 0 & 1 & 1 & 3 & 0 & 0 & 5 & 203 \\
\hline
\end{tabular}

In her final draft, most of the mistakes were corrected but she could not identify the punctuation problems:

Colombia has many types of dishes. People in Colombia are happy _ as well as_kind; besides_each region has typical and special customs. Colombia food is influenced by Asian cuisine, Arabic cuisine, but especially by Spanish _ since this country conquered indigenous populations that were inhabitants of those lands.

The text had well-stated ideas and arguments in its introduction as well as supporting paragraphs and the conclusion: "To sum up, Colombian food is very varied, since it has been influenced by other countries and it has its own dishes, recipes and custom_, that makes Colombian cuisine unique and delicious." Table 4 shows the progress made in each composition:

Table 4. Third Written Production Overall Recurrent Errors

\begin{tabular}{|l|c|c|c|c|c|c|c|c|}
\hline $\begin{array}{c}\text { History of } \\
\text { Colombian } \\
\text { Food }\end{array}$ & $\begin{array}{c}\text { Spellin } \\
\mathrm{g}\end{array}$ & Grammar & $\begin{array}{c}\text { Voca- } \\
\text { bulary }\end{array}$ & $\begin{array}{c}\text { Punc- } \\
\text { tuation }\end{array}$ & $\begin{array}{c}\text { Capitali- } \\
\text { zation }\end{array}$ & $\begin{array}{c}\text { Run-on } \\
\text { sentences }\end{array}$ & Total & $\begin{array}{c}\text { Word- } \\
\text { count }\end{array}$ \\
\hline Draft 1 & 3 & 6 & 5 & 6 & 0 & 0 & 20 & 157 \\
\hline Draft 2 & 3 & 6 & 4 & 3 & 0 & 0 & 16 & 157 \\
\hline Final version & 0 & 0 & 0 & 3 & 0 & 0 & 3 & 157 \\
\hline
\end{tabular}


In the fourth composition, this text explained key ideas in order to make presentations. It was organized in well-developed paragraphs, but there were some problems with word choice, word form, and punctuation:

A good presentation, including visual helps like posters; besides, this it should have the information organized; for example_ the presentation about Mexican food had three important aspects: First of all; it was geographical aspects that included the six regions in Mexico.

In her text, she could write information about Mexican food history and important aspects in order to put together a better presentation.

In her second draft, she could correct the majority of the mistakes:

A good presentation includes visual aids like posters; besides, it should have the information organized; for example, the presentation about Mexican food had three important aspects: First of all; they were geographical aspects that included the six regions in Mexico.

Occasionally, she had problems with word choice. In her final draft, the text was properly corrected:

A good presentation includes visual aids like posters; besides, it should have the information organized; for example, the presentation about Mexican food had three important aspects: First of all; there were geographical aspects that included the six regions in Mexico.

She could write a well-organized text with a good flow of ideas including an introduction, a supporting paragraph, and a conclusion:

So a good presentation not only has visual aids_ but also_ it should have the most important information, in conceptual maps or slides, it depends on each person. Also, it should have self-confidence of topic, since, it will make that the people understand all information.

The most common mistakes were punctuation and word choice. However, the ideas were appropriately divided into paragraphs with supporting details. Table 5 shows the progress made in each composition.

Table 5. Fourth Written Production Recurrent Errors

\begin{tabular}{|l|c|c|c|c|c|c|c|c|}
\hline $\begin{array}{c}\text { Mexican Food } \\
\text { Through } \\
\text { Regions }\end{array}$ & Spelling & Grammar & $\begin{array}{c}\text { Voca- } \\
\text { bulary }\end{array}$ & $\begin{array}{c}\text { Punc- } \\
\text { tuation }\end{array}$ & $\begin{array}{c}\text { Capita- } \\
\text { lization }\end{array}$ & $\begin{array}{c}\text { Run-on } \\
\text { sentences }\end{array}$ & Total & $\begin{array}{c}\text { Word- } \\
\text { count }\end{array}$ \\
\hline Draft 1 & 0 & 5 & 6 & 2 & 0 & 0 & 11 & 98 \\
\hline Draft 2 & 0 & 3 & 3 & 2 & 0 & 0 & 6 & 98 \\
\hline Final version & 0 & 2 & 1 & 2 & 0 & 0 & 5 & 98 \\
\hline
\end{tabular}


In her fifth composition, "How to Make a Milkshake," she could write appropriate instructions for making a milkshake: "Serve in tall glass the mixture. And add whipped cream if you like, and put two or more cherries on the top." She wrote a clear and well-organized text. It was also an accurate text although there were some errors regarding form. Regarding content, it only omitted a few important pieces of information from the presentation such as the history and the current perceptions of the drink.

In her second draft, the mistakes were properly corrected: "Serve the mixture in [a] tall glass. Add whipped cream if you like and put two or more cherries on the top." She also included the missing information with mostly complete sentences based on the most important details of the presentation: "Milkshake is very famous around the world, and it is used in fast-food restaurants, schools, and it has added new ingredients for its sale."

In her final draft, there were some omission of words and word choice but the text was well-formed: "Serve the mixture in _ tall glass. Add whipped cream if you like and put two or more cherries on the top." She also included the missing information with mostly complete sentences based on the most important details of the presentation: "Milkshake is very famous around the world, and it is used in fast-food restaurants, schools, and new ingredients has added for its sale." Table 6 shows the progress made in each composition.

Table 6. Fifth Written Production Recurrent Errors

\begin{tabular}{|l|c|c|c|c|c|c|c|c|}
\hline $\begin{array}{c}\text { How to Make } \\
\text { a Milkshake }\end{array}$ & Spelling & Grammar & $\begin{array}{c}\text { Voca- } \\
\text { bulary }\end{array}$ & $\begin{array}{c}\text { Punc- } \\
\text { tuation }\end{array}$ & $\begin{array}{c}\text { Capita- } \\
\text { lization }\end{array}$ & $\begin{array}{c}\text { Run-on } \\
\text { sentences }\end{array}$ & Total & $\begin{array}{c}\text { Word- } \\
\text { count }\end{array}$ \\
\hline Draft 1 & 0 & 4 & 0 & 0 & 0 & 0 & 4 & 82 \\
\hline Draft 2 & 0 & 4 & 0 & 0 & 0 & 0 & 4 & 114 \\
\hline $\begin{array}{l}\text { Final } \\
\text { version }\end{array}$ & 1 & 3 & 0 & 0 & 0 & 0 & 4 & 115 \\
\hline
\end{tabular}

In general terms, the student wrote her own ideas in her compositions and developed a complete structure following a pattern of introduction, supporting paragraphs, and a conclusion. However, she had problems with punctuation, word order, and word choice. In the process she showed that she had improved and had written more accurate and better-organized texts thanks to the prewriting techniques. Her answers to the questionnaires indicated that she had learned to write better. For instance, in the question, "What did you learn in the first term?" she wrote, "I learned to write in English with the correct grammar and structure, I made two outlines about food, and they make 
my writing process more easy." She realized that the pre-writing techniques facilitated her writing process although she recognized that writing was not easy at all in the first term: "One problem I had was learning the correct structure about English; because it is so confused and specific."

For the second term, another questionnaire was applied. One question was: "How much do you think you have benefited from the second term?" She wrote:

I think that I have benefited in the area of food vocabulary since I learned new words and new expressions. Also I have benefited in writing due to the exercises do in class and in my house, for example Chamilo where I did many exercises about grammar_especially passive voice and modal verbs.

According to her, she could learn vocabulary and write more accurately thanks to the grammar practice and the processes being made both during and after the class.

In the question, "What did you think you learned in the second term?" she answered that she had learned a lot of valuable things:

In the second term I learned food vocabulary: principally Colombian food, since I was in a presentation that my partners did about this topic. Exactly because they speak about Colombian regions. I learned to make a recipe with the tips, process (including ingredients and cooking utensils). I would also say that I learned history of some important dishes in my country. For example, Ajiaco, Gamitana Rellena, Mamona.

She not only learned about writing, but also about her country, and from her peers. When she participated in peer feedback, she wrote with a persuasive tone about writing and she gave her partner useful feedback:

I think that she would be better if she puts topic sentences in each paragraph. Also I believe she needs to put more linking words to support the main ideas. She had a good grammar but she would be more specific in the sentences.

When she received feedback from her partner, her classmate wrote similar comments: "I think that _ is important _ write the text with more sentence_ and use more connecting of word."

In the final questionnaire, she showed she was optimistic about her progress in writing. Additionally, she recognized the importance of the writing process approach (see Table 7).

Concerning the question "Do you have any comments about project work or suggestions which have not been covered by the questions above?" she added some comments about her learning: "The project was very interesting and I like[ed] it so much. I think that this project was useful for my process of learning." She had a positive view towards learning with the project. 
Table 7. Final Questionnaire

\begin{tabular}{|l|l|}
\hline How much do you think you have benefited from the English project? & A lot \\
\hline How important is the teacher's feedback in writing classes? & High \\
\hline How often do you follow the teacher's comments in your revisions? & Always \\
\hline Are the teacher's comments in your compositions easy to understand? & Yes \\
\hline How useful are the teacher's comments in your compositions? & Always useful \\
\hline Rate your performance as an English learner BEFORE the project. & Good \\
\hline Rate your performance as an English learner AFTER the project. & Excellent \\
\hline Rate your performance as an EFL writer BEFORE the project. & Average \\
\hline Rate your performance as an EFL writer AFTER the project. & Good \\
\hline
\end{tabular}

Broadly speaking, the student began with a good text in her diagnostic test. She wrote long texts, but there were many mistakes such as isolated phrases without connecting her ideas, and problems with spelling and punctuation. The process gave her useful tools for writing more organized texts with a suitable body: introduction, supporting paragraphs, and conclusion. She also organized her sentences better by using linking words although she also wrote that one of the biggest challenges in the process was using linking words: "The most difficult was the beginning since I didn't know some expression[s]_ and linking word[s] for my learning process." Each correction showed a lot of improvement, but she still had problems with word choice and punctuation. She still had a lot of work to do to learn about the complexities of writing, but she had an optimistic view about her learning as a writer because she thought that she had improved from average to good. According to her opinion in the feedback section, we could see that she had not only learned the concepts of topic sentences, main ideas, and supporting ideas, but that she had also showed its importance in the process of writing.

\section{Findings}

\section{Accuracy}

Accuracy is defined as the ability to produce correct sentences using suitable vocabulary and suitable grammar. Accuracy refers to "the similarity to native speaker grammar in the case of L2, or to prescriptive grammar in the case of L1" (Paradis, 2009, p. 6). Students improved 
accuracy in writing. Before the implementation of the project, students got a very low score in the vocabulary and grammar section of the diagnostic test and that weakness was very much reflected in their writing compositions. They often had local errors such as subject-verb agreement, tenses, plural-s, word choice, spelling, redundancy, missing words, word order, missing punctuation, omission of capitalization, omission of linking words, and they even customarily translated literally from Spanish to English. The incorrect use of grammar impeded the understanding of their compositions, and each revision was full of proofreading marks. Students almost always asked for the teacher's assessment after their drafts, because they did not know how to correct their work and they had to write multiple drafts until the text was ready.

After almost four months (15 weeks) of project work implementation, the quality of the students' compositions, specifically their grammar structures, had improved. Their drafts had fewer mistakes and students asked for the teacher's assessment less often during the writing process. Instead, they corrected them by themselves and through peer feedback. For instance, Figure 3 shows the total sum of mistakes in each draft regarding form, especially the first compositions about the topic, "How to Learn English," and it also shows that those mistakes decreased in each correction of the same topic because they were corrected in each composition.

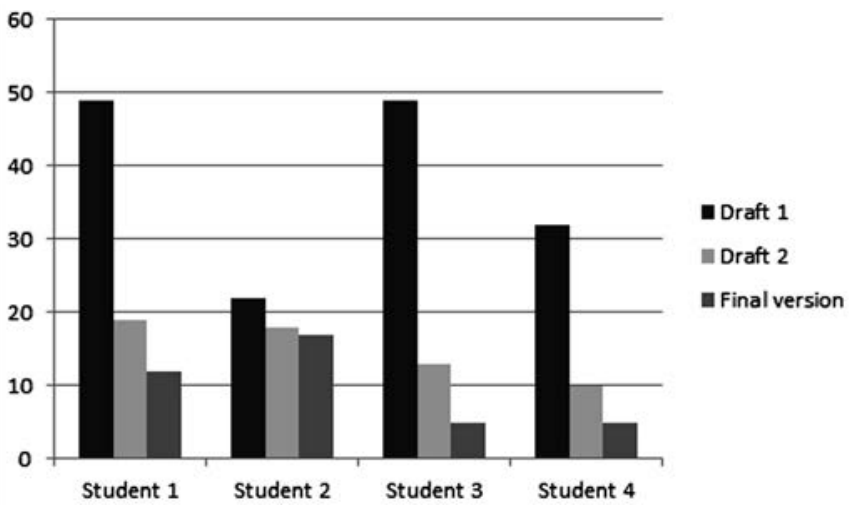

Figure 3. Total Sum of Mistakes in Each Correction of the Writing "How to Learn English"

These strategies adopted by students showed that there was a heightened awareness of language accuracy. However, it is important to clarify that their grammatical proficiency still affects their compositions. For instance, students still had to stop to translate often and they 
usually make mistakes about word choice, word form, and word order, among others, but with less frequency. Figure 4 shows the total sum of mistakes in each composition, and it also shows the decreased frequency of mistakes in the next composition.

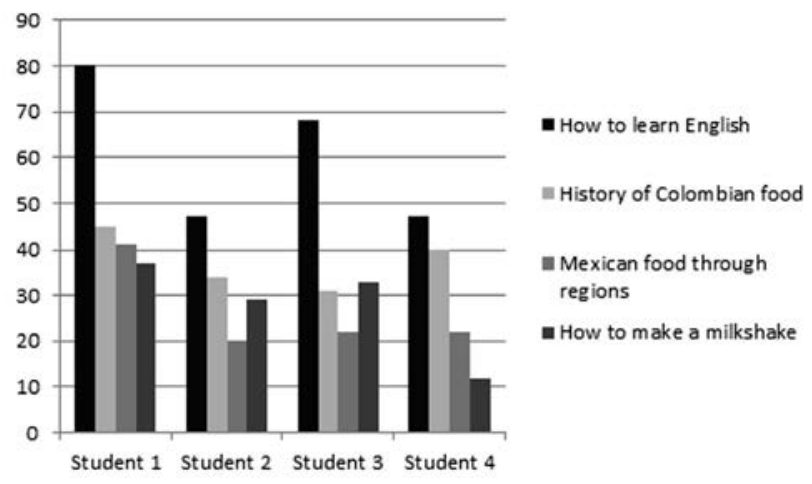

Figure 4. Total Sum of Mistakes of Each Correction of the Four Compositions

In fact, it is important to highlight that the process of better accuracy is exemplified better in the case of Student 2 and Student 1, who were graded oppositely from each other since Student 2 got a low score while Student 1 got a high score. Moreover, better accuracy does not imply a total absence of mistakes. As is shown in Figure 5, students were able to improve their compositions, but even in the last composition there were still mistakes.

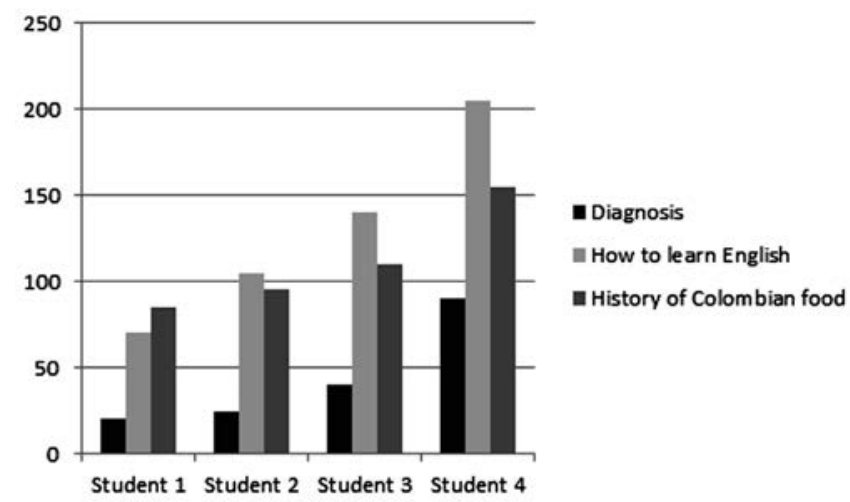

Figure 5. Length of Each Narrative Text 


\section{Fluency}

How students modified their writings in terms of length was also identified, better organization of ideas, and speed for writing, which are the first basic elements for beginning the process of obtaining fluency. Fluency is defined as the ability to speak, write, and read smoothly and meaningfully. Fluency refers to "the absence of pauses and other indices of word-finding (or grammatical) difficulty" (Paradis, 2009, p. 6). Before implementing project work, students used to write very short and simple texts, although they were expected to write longer texts with the principal characteristic of being well-supported compositions. Students could not write a very well-organized composition. For instance, they did not follow a structure of introductions, supporting paragraphs, and conclusions. In the first draft, they were supposed to write texts of roughly a 150 words, but most of them only wrote some isolated ideas without argumentation. They said that they did not know what else to say in their texts. Additionally, they did not use any prewriting techniques. After the implementation of project work, the students wrote longer texts with a more complex development of ideas. Figure 5 shows the length (word-count) between the narrative texts ("How to Learn English" and "History of Colombian Food") and the texts in the diagnostic test.

The length of the narrative texts is greater that the length of the texts in the diagnostic test. When writing the narrative texts, students were provided with vocabulary, readings concerning the topics, grammar structures, and prewriting techniques such as outlining and brainstorming. Those tools gave them the ability to write longer essays. Figure 6 shows the length (word-count) between the summaries ("Mexican Food Through Regions" and How to Make a Milkshake"), and the texts in the diagnostic test.

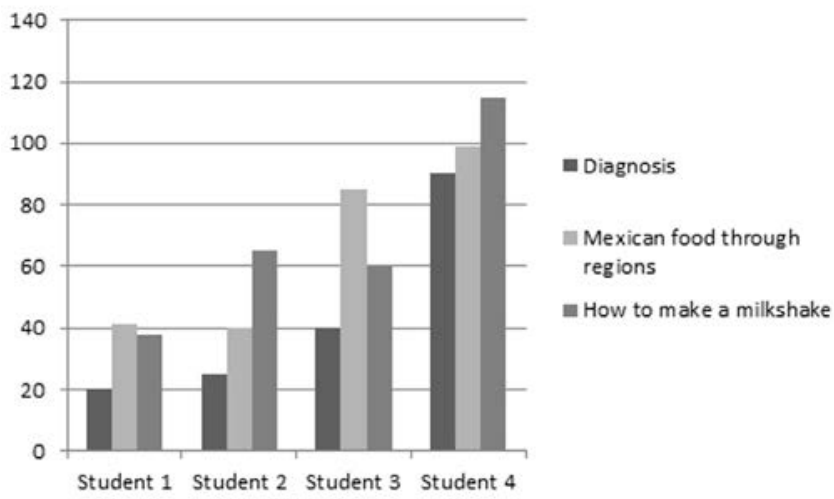

Figure 6. Length in Each Summary 
The length of the summaries is much greater than the length of the diagnostic test composition. In addition, the students spent more time planning the overall organization which made their compositions more accurate and fluent. For instance, one of the best and more well-developed compositions with fewer grammar mistakes was the composition about the history of Colombian food because students had to research and read about the topic; later they participated in a debate about it; after that they wrote an outline, and then they were able to write their compositions with a more complex organization, suitable vocabulary, and proper grammatical structures.

Students wrote faster after the implementation of project work. In the first compositions, students used to stop, write, erase, ask the teacher for help, and so on. But later, they began to use their prewriting techniques without needing as much of the teacher's help. This process allowed students to write with fewer interruptions and enabled them to include more refined ideas in well-structured paragraphs. However, it is important to clarify that writing is a very complex skill and becoming a fluent writer takes work. In this sense, students were able to expedite the process leading to fluency.

\section{Integrative Language Skills}

In spite of the fact that this study focuses on writing feedback, we should not see writing as an isolated language skill. The implementation of project work has positive effects on students' written production, and the emphasis on the writing process has positive effects on students' oral production as Madrid and McLaren (1995) suggested (that written practice supports oral proficiency because it is feasible to integrate language skills for communicative purposes). Before the implementation of project work, students refused to speak in English on the diagnostic test. In the debate about the history of Colombian food, some students remained quiet most of the time, and the ones who spoke only mentioned a couple of isolated ideas without supporting ideas.

In the first presentation about Colombian food by regions, students were more organized in their speaking and used linking words. However, there were common, incorrect grammar structures and most of them dealt with reading rather than speaking. In the second presentation about Colombian recipes, students appeared more confident. There were fewer grammatical structure mistakes and this time students were able to speak more and read less. Students spoke more naturally in their explanations about Colombia and the recipes.

In the final presentation about the interview of a foreign person, students took the risk to ask the person the questions and some of them dared to go further than the pre-established questionnaire and others were even able to engage in a more natural conversation with the foreigner and included more questions that emerged naturally. Three of the groups not only liked the activity but also decided to interview more foreigners in order to include them in 
their videos. It means that according to their production and the students' opinions written in the feedback sections, they were able to improve their accuracy, length, organization of ideas and writing speed, and those improvements positively influenced their oral production and confidence in speaking English.

\section{Students' Perceptions on Writing}

Before the implementation of project work, students had a negative perception about writing. Twenty-nine percent of the students refused to write in the diagnostic test and most of the students agreed that one of the most difficult parts of the diagnostic test was the writing section. They did not like to write in English since they considered writing and speaking to be the most difficult skills to master in English. When they were asked about problems they had in the first term, most of them mentioned problems with pronunciation, vocabulary, speaking well, writing well, and organizing their ideas in the compositions. In the final questionnaire, they thought they were awful English writers prior to the project, but after the project their self-perception improved and they considered themselves better writers. The students were asked to write and nobody refused to do it.

Assessment has also contributed to the positive perception about writing. In the final questionnaire, the students expressed that the teacher's assessment, feedback sessions, and proofreading marks were very important in learning to write better. Direct feedback from the teacher, according to the students, significantly helped them in identifying key strengths and weaknesses which improved the draft writing process. The self-evaluation provided good opportunities to reflect on the writing process. Peer feedback also provided good opportunities to read others' compositions. This activity showed that students knew the principal characteristics for organizing a composition better since they could realize their partners' problems and offer useful recommendations. The peer feedback sheet also facilitated this process. When students were asked to give their opinion on peer feedback, most of them expressed that they considered the feedback sessions new, useful, and interesting.

The project was very good, we learn variety of things of our country, our food in other language.

The project was good development and it was process and a good direction. (Student 2)

These student-centered activities increased overall student participation and motivated the students to learn more about effective writing, because they had the opportunity to talk, express their opinions in the classroom, and give feedback to their partners. After evaluating their writings and feedback activities, I saw that the implementation of project work provided good opportunities for students to write with improved structure and better organization. Although many students improved their writing skills, not all of the students improved at a rapid pace. Writing is a complex skill and cannot be mastered in such a low-level English 
course. It implies that the project was only the first step towards mastering communicative English skills, although the students felt they had improved significantly in their compositions, speaking, reading, and grammar, among other aspects of learning a language.

\section{Conclusions}

Project-based learning and a process approach seem to be effective implementations because they can heighten the writing abilities and confidence of students who are learning English. According to their production and students' opinions written in the feedback sections, they were able to improve the accuracy in their writing skills in areas such as structure, length, organization of ideas, and speed for writing, and those improvements positively influenced their speaking production and their perception towards writing and learning. Although students have not mastered the productive skills of writing and speaking yet, and although they frequently have problems with accuracy, fluency, and pronunciation, their writing skills improved.

\section{Implications and Limitations}

The findings of this study have a number of important implications for future practice. A longer study is recommended in order to examine the changes in students' perceptions and written production. It should be carried out in many other EFL writing and oral classes. This study is an opportunity to develop writing skills when implementing project work and process approach since project work required a process approach to develop written production through feedback. It is also a suitable example for teachers who would like to update their teaching practice. The teachers of English can work with project-based learning because it does not require expensive resources and it is flexible where the academic calendar, the curriculum, and students' interests are concerned.

Teachers should include students' ideas to plan and develop the project because they are active doers. The writing topics and materials should be authentic and relate to students' daily lives since they were more motivated and increased their level of understanding with authentic projects and problems. The teacher could provide comprehensible input about the assigned topics, encourage students to find information, organize their ideas before writing, and become engaged in self and peer correction due to the fact that students provided each other recommendations when writing (see Figure 7).

Have you got any recommendations for improvement? What did you like/dislike about the paragraph (e.g., ideas, vocabulary, well-supported examples, etc.)? 


\section{I think that my classmate can improve in gramatic. spelling and she could write some examples for supporting her ideas. I like about the paragraph the writer starked with the topic sentence always.}

Figure 7. Student Peer Feedback

Some pre-writing techniques such as brainstorming and outlining should be implemented. The teacher should focus more on content than on form when providing feedback.

The findings in this study are subject to at least two limitations. First, time constraints affected qualitative research. The project only lasted 15 weeks, a total of 45 hours. Second, the time limit also affected the sample size of this study since only four students' writings were explored. More reliable results would probably have been achieved if the study had been implemented for a longer time and with a larger sample. Both the students and the teachers must consider multiple factors such as a student-centered classroom, metacognition strategies, and the use of a methodology that can be adapted in a classroom for effective learning. This is the case of project-based learning which focuses on production and metacognition and is able to promote effective feedback because students can engage in meaningful situations in order to learn a language. Finally, a multiple-case study on writing classes from various universities should be attempted. Further research might explore teachers' beliefs before and after the implementation of project work when teaching writing.

\section{References}

Bluestein, J. (2001). Creating emotionally safe schools: A guide for educators and parents. Deerfield Beach, FL: Health Communications.

Fried-Booth, D. (2002). Project work (2 $2^{\text {nd }}$ ed.). New York, NY: Oxford University Press.

Haines, S. (1989). Projects for the EFL classroom: Resource material for teachers. China: Nelson and Sons.

Hopkins, D. (2002). A teacher's guide to classroom research (3 ${ }^{\text {rd }}$ ed). Berkshire, UK: Open University Press.

Hyland, K. (2003). Second language writing. Cambridge, UK: Cambridge University Press. 
Legutke, M., \& Thomas, H. (1991). Process and experience in the language classroom. New York, NY: Longman.

Madrid, D., \& McLaren, N. (1995). Didactic procedures for TEFL. Valladolid, ES: La Calesa.

Paradis, M. (2009). Declarative and procedural determinants of second language. Philadelphia, PA: John Benjamins Publishing Company.

Ribé, R., \& Vidal, N. (2003). Project work: Step by step. Oxford, UK: Heinemann.

Stoller, F. (1997). Project work: A means to promote language and content. English Teaching Forum, 35(4), 29-37.

Stoller, F. (2002). Project work: A means to promote language and content. In J. C. Richards \& W. A. Renandya (Eds.), Methodology in language teaching: An anthology of current practice (107-120). Cambridge, UK: Cambridge University Press.

Wallace, M. J. (1998). Action research for language teachers. Cambridge, UK: Cambridge University Press.

\section{The Author}

Marcela Díaz Ramírez completed her master in Applied Linguistic for teaching English as a foreign language at Universidad de Jaén, Spain. She has participated in a teacher education program at Universidad La Gran Colombia and she is working at Universidad de Cundinamarca, Colombia. 